\title{
Studies of Climate Change with Statistical-Dynamical Models: A Review
}

\author{
Sergio H. Franchito, Vadlamudi B. Rao \\ Centro de Previsão de Tempo e Estudos Climáticos, CPTEC, Instituto Nacional de Pesquisas Espaciais, INPE, \\ São José dos Campos, Brazil \\ Email: raovtz@yahoo.com.br, sergio.franchito@cptec.inpe.br
}

Received 18 February 2015; accepted 9 March 2015; published 12 March 2015

Copyright $@ 2015$ by authors and Scientific Research Publishing Inc.

This work is licensed under the Creative Commons Attribution International License (CC BY).

http://creativecommons.org/licenses/by/4.0/

(c) (1) Open Access

\begin{abstract}
The cause-effect relationship is not always possible to trace in GCMs because of the simultaneous inclusion of several highly complex physical processes. Furthermore, the inter-GCM differences are large and there is no simple way to reconcile them. So, simple climate models, like statisticaldynamical models (SDMs), appear to be useful in this context. This kind of models is essentially mechanistic, being directed towards understanding the dependence of a particular mechanism on the other parameters of the problem. In this paper, the utility of SDMs for studies of climate change is discussed in some detail. We show that these models are an indispensable part of hierarchy of climate models.
\end{abstract}

\section{Keywords}

\section{Simple Climate Models, Statistical-Dynamical Models, Climate Change}

\section{Introduction}

Although the ideal tool for the numerical simulation of climate change would be a fully-resolved three-dimensional model, General Circulation Models (GCMs) are not yet able to represent adequately the physical processes of climate and climate change and consequently there are uncertainties for climate change sensitivity. Thus, there is need for the spectrum of models of differing levels of complexity to investigate the climate behaviour, each being optimum for answering specific questions [1]. In this context, simpler climate models are useful to understand large-scale processes and feedbacks acting within the climate system. In addition, simple models are computationally more economical than GCMs and it is relatively easy to analyze and diagnose their behaviour. They can be employed as tools to emulate and understand GCM results.

The simplest climate models are the one-dimensional radiative-convective models (RCMs) [2]. The RCMs 
usually incorporate relatively detailed treatment of radiative processes and permit for example investigation of the consequences of global scale changes in atmospheric composition. Normally RCMs give only the vertical profile of global mean temperature. Within the class of one-dimension climate models lie the energy balance models (EBMs) wherein vertical integration is done in order to treat latitudinal variation of the climate in terms of surface temperature [3] [4].

An intermediate class of models are the zonally averaged climate models (ZACMs) in which the treatment of radiative processes can be as sophisticated as in the GCMs but somewhat simplified from the detailed RCMs. While the RCMs and EBMs consider only the thermodynamics of the system, ZACMs include the treatment of dynamics usually by allowing two atmospheric layers. Although the synoptic systems are not included explicitly, their statistical effects are included through parameterization [5]-[11]. Because of this, ZACMs are referred as statistical dynamical climate models (SDMs), although some prefer to make a further distinction [12]. Another advantage of SDMs in comparison with RCMs and EBMs is the inclusion of both latitudinal and vertical variation, thereby permitting more explicit treatment of many feedback mechanisms that must be simplified in the one-dimensional models. While RCMs can treat the vertical structure of the atmosphere, SDMs can additionally estimate the latitudinal characteristics of the response. SDMs are essentially mechanistic, being directed toward understanding the dependence of a particular mechanism on the other parameters of the problem. This is an advantage in comparison to GCMs since the cause-effect relationship is not always possible to trace in these models due to the simultaneous inclusion of several highly complex physical processes. Furthermore, the inter-GCM differences are large and there is no simple way to reconcile them. Since the SDMs are much more computationally efficient than GCMs they can be useful for long-term climate variation studies. In spite of their usefulness they have some restrictions such as the loss of regional resolution. An additional constrain is the errors and limitations that are necessarily introduced in the attempt to parameterize eddy transports based on zonally averaged quantities. Because of their intermediate position, SDMs can be helpful in the design and analysis of GCM studies and in generalizing the results of simple EBM and RCM studies.

Thus, SDMs can be thought of as making a bridge between simpler EBMs and sophisticated GCMs. In a series of papers Franchito and Rao and their collaborators showed the feasibility of using SDMs to study climate change [13]-[22]. In the present work a review of several studies of climate change with SDM is presented. Section 2 shows numerical experiments: Section 2.1 presents the simulation of the annual cycle; Section 2.2 shows the experiments of climate change due land surface alterations; Section 2.3 presents the experiments of climate change due to global warming; and Section 3 presents the latest advances by using statistical-dynamical models; conclusions are shown in Section 4.

\section{Numerical Experiments with SDMs}

\subsection{Simulation of the Annual Cycle}

\subsubsection{Simulation of the Annual Cycle of the Atmosphere and Sea Surface Temperature}

Since the earth's climate change undergoes significant and gross predictable seasonal changes, a useful test of the validity of a climate model is the ability to simulate the annual cycle. [23] using a two-layer primitive equation SDM simulated the mean annual conditions and zonally averaged atmosphere. In a subsequent paper, [14] applied the model to simulate the sea surface temperature (SST). For this purpose, they assumed that at all latitudes the surface was considered to be covered only by water. The objective was to investigate how well the surface energy balance alone determines SST since no ocean dynamics was included in the model. The results showed that the gross characteristics of the mean annual SST and its seasonal cycle were well simulated by the model. The results suggested that the radiative processes play a fundamental role in determining the SST patterns.

\subsubsection{Simulation of the Monsoon-Like Circulations}

What characterizes monsoon is the annual variation. The monsoon is associated with a reversal of $180^{\circ}$ in the low-level winds from winter to summer. SDMs can effectively be used to study the dynamics of the monsoon. [24]-[27] conducted a series of experiments with ZACMs where the Asiatic continent and adjacent oceans were included. [24] considered a dry monsoon model (i.e., no hydrological cycle) allowing only the effect of a heating differential between an interactive and evolving ocean and the land. The major result was the importance of the east-west ocean land contrast. [25] [26] extended the model scheme to include a full hydrological cycle and compared difference in both the mean seasonal model monsoon and the subseasonal variability of the model 
monsoon. [27] using the zonally symmetric model of [25] performed a number of experiments in which the physical complexity of the system was successively increased. He found that only with hydrological cycle the low frequency modulations occurred. In these studies the effects of the topography were not taken into account.

[16] used a two-layer primitive equation SDM to verify its ability to capture some monsoon-like variations and to investigate the effects of the topography in the monsoon-like circulation. For this purpose they include into a model a smoothed zonally averaged topography that had a form similar to that observed. The results showed that the model was able to capture some basic characteristics of the monsoon-like circulation such as the seasonal wind reversal (Figure 1(a) \& Figure 1(b)). Also, the upper-tropospheric easterly jet in the summer season was well simulated (Figure 1(c) \& Figure 1(d)). They noted that due to the mountain the summer monsoon-like circulation occurred rather suddenly and penetrated farther north. It was also shown that the steepness of the slope (and not the elevation) controls the strength of the monsoon-like circulation in the model.

Other studies have been showed the uselfulness of SDMs to simulate the monsoon circulations not only over Asia but also over West Africa [28]-[31]. The studies regard the effects of vegetation on the monsoon, which will be showed in the next section.

\subsection{Climatic Change due to Land Surface Alterations}

To our knowledge, very few numerical experiments concerning the climatic effects due to land surface alterations have been performed with SDMs. In the experiments of deforestation and desertification realized respectively by [32] [33] the changes in geobotanic state were simulated through the modification of the land surface

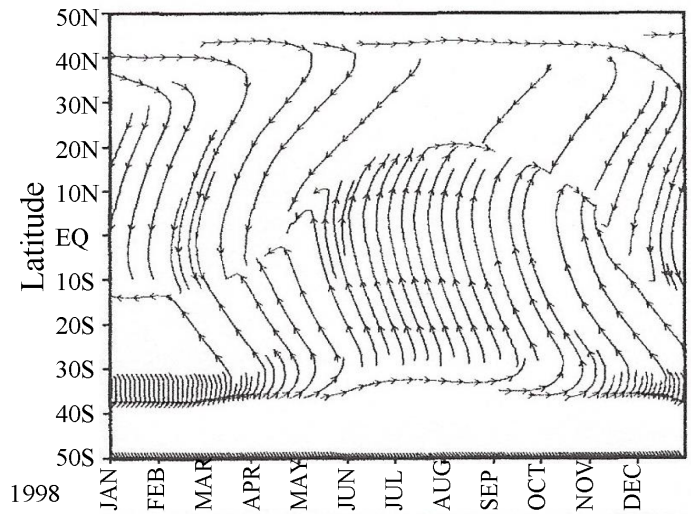

(a)

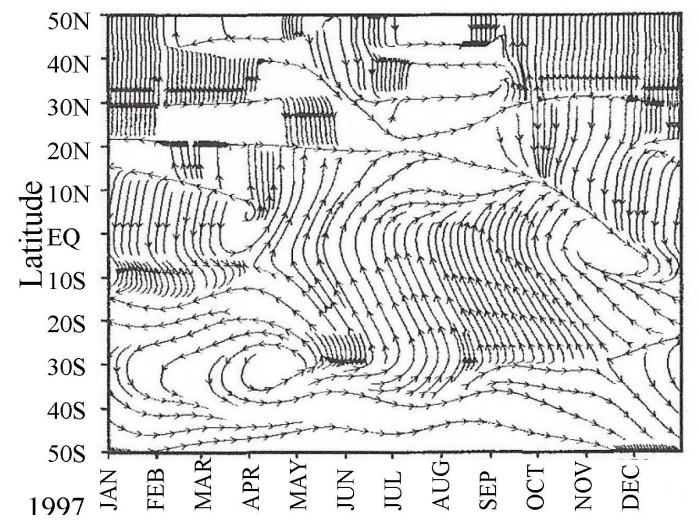

(b)

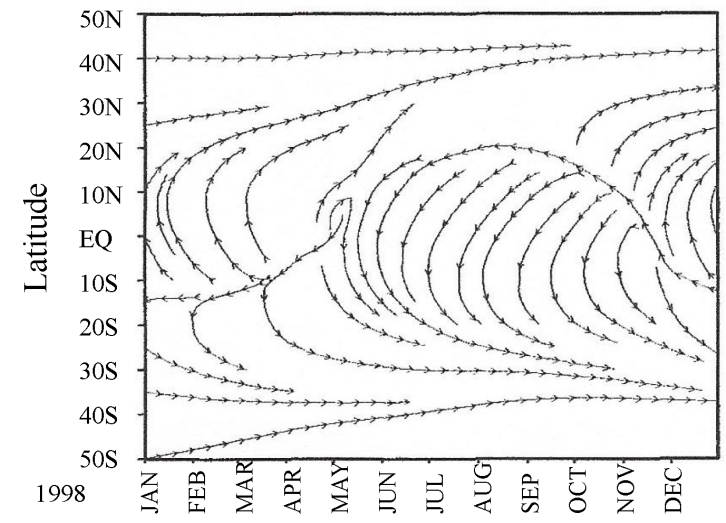

(c)

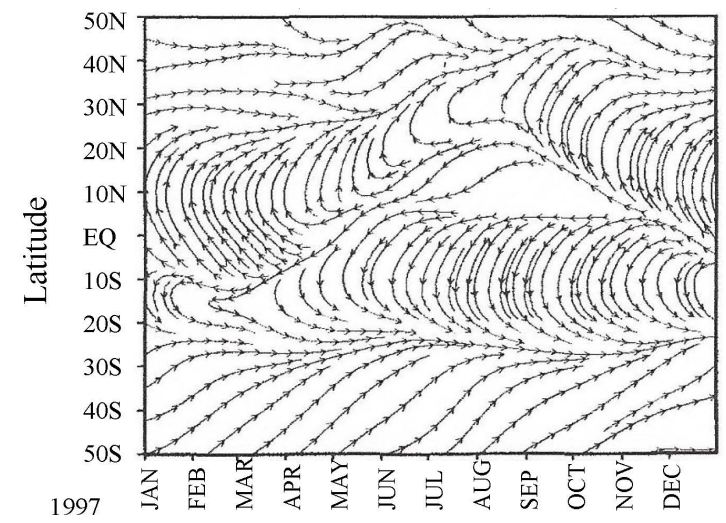

(d)

Figure 1. Annual variation of the stream lines: (a) simulated at $925 \mathrm{hPa}$, (b) observed at $925 \mathrm{hPa}$ and $80^{\circ} \mathrm{E}$, (c) simulated at $250 \mathrm{hPa}$ and (d) observed at $250 \mathrm{hPa}$ and $80^{\circ} \mathrm{E}$. The observed values are obtained from the NCEP-NCAR reanalysis data. The observations were obtained from the NCEP-NCAR reanalysis data along $80^{\circ} \mathrm{E}$, which strongly represent the monsoon. The model winds at $925 \mathrm{hPa}$ were obtained by logarithmic interpolation. (Source: Rao, V. B.; Fernandez, J. P. R.; Franchito, S.H., 2000: Monsoon-like circulations in a zonally-averaged numerical model with topography. Mon. Wea. Rev., 128: 779794. (C) Copyright [2000] American Meteorological Society. Used with permission). 
albedo. However, in these experiments changes in geobotanic state were not considered outside the perturbed region. [34] using a version of [35], incorporated a parameterization of the biofeedback mechanism for the Northern Hemisphere $(\mathrm{NH})$ in which the changes in geobotanic state could also be considered outside the perturbed zone. In this model they considered that a land fraction in each latitude belt was only covered by the predominant type of vegetation. [36] using this SDM, studied the hemispheric response of land surface alterations like deforestation and desertification. The results indicated that the change in evapotranspiration rather than in surface albedo was the predominant effect in regulating the surface temperatures. This is in agreement with that was found by [37] using a GCM.

Although quasi-geostrophic SDMs are adequate for the treatment of the dynamics of the atmosphere in the extratropical region when the interactions between the tropics and higher latitudes are considered the use of the primitive equations is more appropriate. [13] developed a global primitive equation SDM including a biofeedback mechanism based on the parameterizations of [34]. They showed that the global distribution of the geobotanic zones were well simulated by the model (Figure 2). They applied the model to study the climate effects due to deforestation and desertification. The main results in the two experiments were: in both the hemispheres there was a decrease in the surface net radiation, evapotranspiration and precipitation and an increase of the surface temperature in the perturbed areas showing that the decrease in the evaporative cooling overcomes the effect of the increase of the land surface albedo. These results were similar to those obtained by [36]. However, in [13] the changes were obtained in both the hemispheres.

The treatment of the interaction between the surface processes and the atmosphere is very simple in [13]. [15] incorporated a biosphere model based on BATS [38] in that model. Although well-described complex biosphere models such as BATS have been developed for GCMs, their coupling to simpler SDMs is also relevant for the

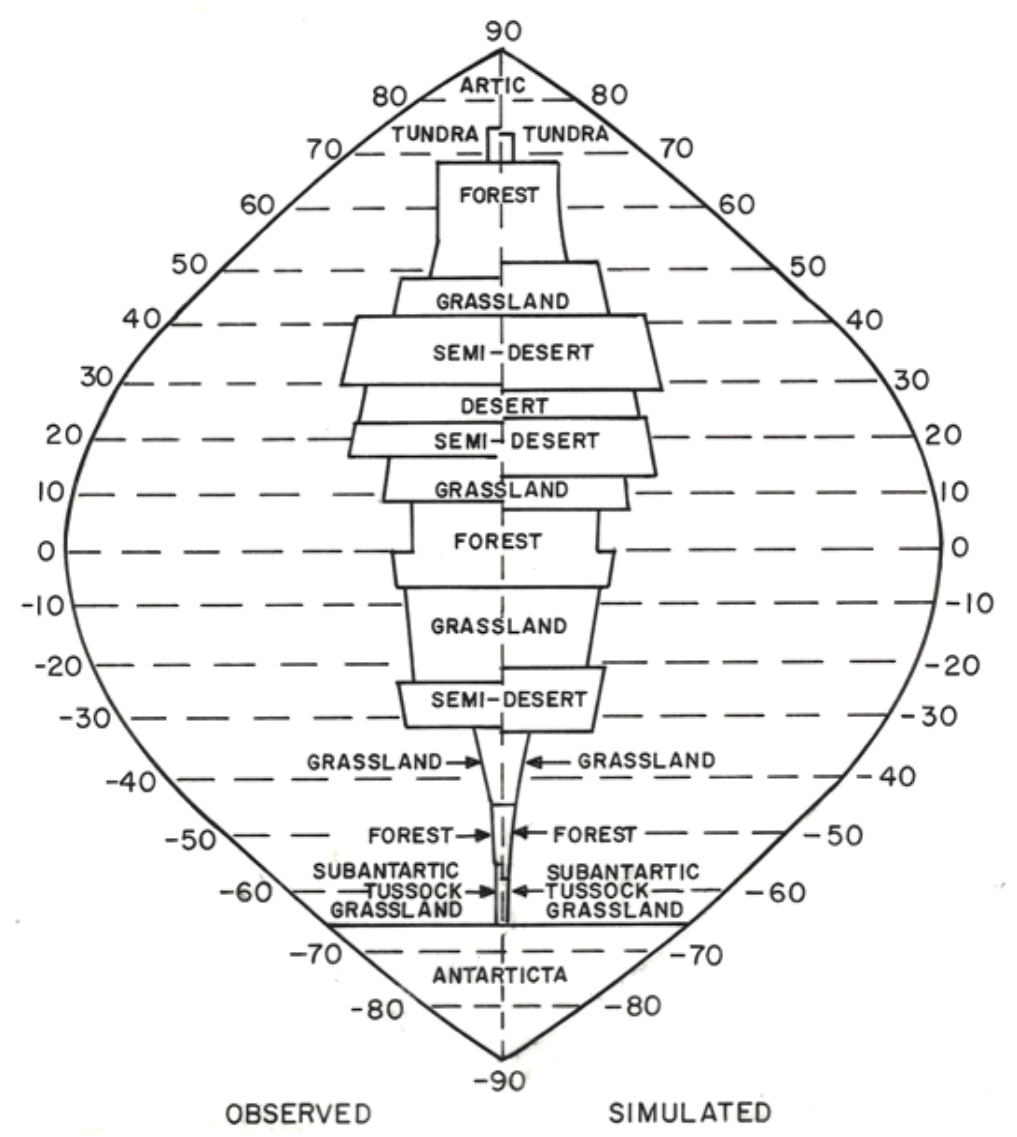

Figure 2. Global distribution of the geobotanic zones simulated by the model (right) and observed (left). (Source: Franchito S. H.; Rao, V. B., 1992: Climatic change due to land surface alterations. Clim. Change, 22, 1-34. (C) Copyright [1992] Springer. Used with permission). 
study of the interactions between vegetation and climate because SDMs greatly simplify analysis and aid the identification of biogeophysical mechanisms. The energy fluxes were computed separately for the land fraction and the remaining part (covered by ocean-ice-snow) of the latitudinal belt. The parameterizations of the biosphere model based on BATS were used for the land fraction of the latitude belt. The biosphere model contained four domains: the subsurface layer, the foliage layer, the air foliage layer and two atmospheric layers (from the surface to $500 \mathrm{hPa}$ and from $500 \mathrm{hPa}$ to the top of the atmosphere). The model involved parameterizations of the energy balance of the Earth's surface, the energy and moisture balances of the foliage air layer and the energy balance of the foliage. The model was applied to study the climate impact due to deforestation and desertification. In the deforestation experiment, the evergreen broadleaf tree in the Amazonian region was substituted by short grass (Figure 3(a)). In the desertification experiment the climatic impact of an anthropogenic degradation of the vegetation situated southward of the Sahara desert was simulated. The land surface modification consisted in the substitution of semi-desert by desert, and tall grass and deciduous shrubs by desert and semi-desert, respectively, in the African continent from $0^{\circ}$ to $20^{\circ} \mathrm{N}$ (Figure 3(b)). The model results were consistent with those obtained from other SDMs, which used parameterization of the biofeedback mechanisms much simpler than BATS [13] [36]. However, in the earlier studies the perturbation was imposed in the entire land fraction of the latitude belt, whereas in [15] the effects of a land surface modification in a determined region of a latitude belt, such as Amazonian deforestation and land degradation southward Sahara desert, can be investigated. The results regarding the changes in the temperature and in the energy fluxes were also in agreement with those of earlier experiments carried out with sophisticated GCMs, which shows the usefulness of this kind of simple model.
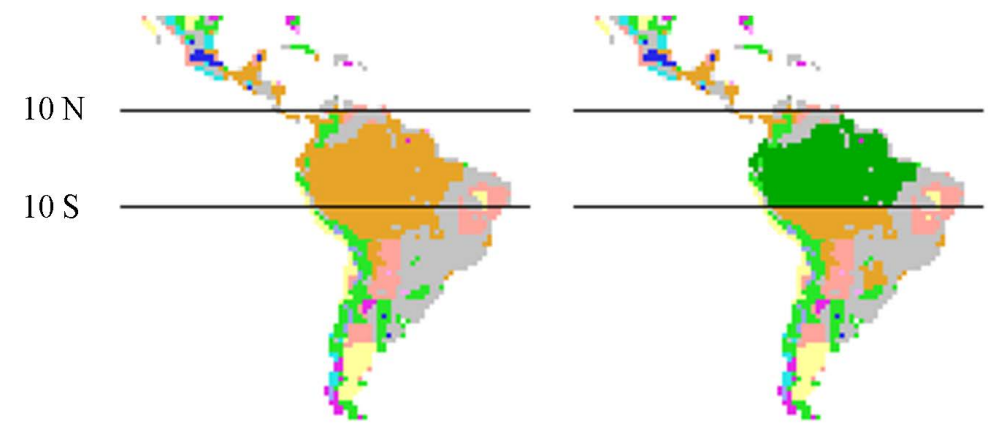

(a)
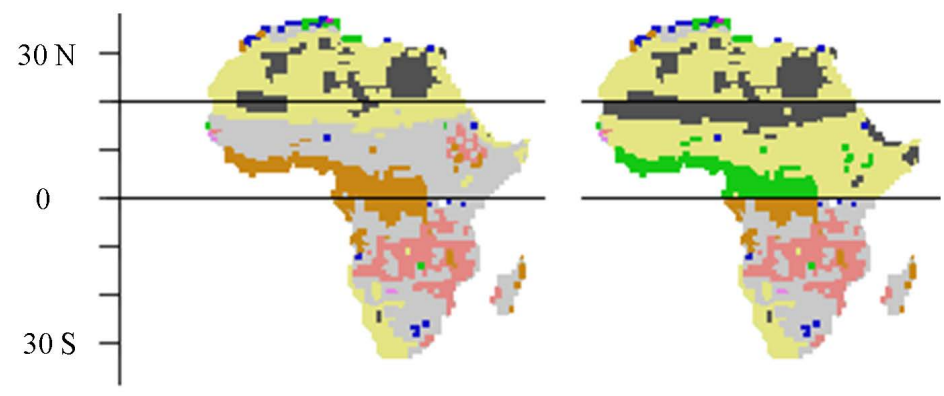

(b)

CROP/MIXED FARMING

SHORT GRASS

EVERGREEN NEEDLELEAF TREE

- DECIDUOS NEEDLELEAF TREE

- DECIDUOS BROADLEAF TREE

- EVERGREEN BROADLEAF TREE

- TALL GRASS

- DESERT

- TUNDRA

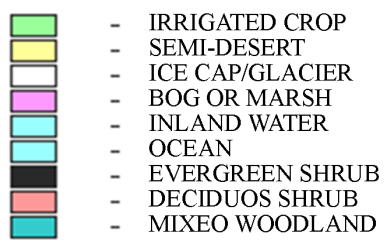

(c)

Figure 3. Change in the biomes in: (a) the deforestation experiment and (b) the desertification experiment. (Source: VarejãoSilva, M. A.; Franchito, S. H.; Rao, V. B., 1998: A coupled biosphere-atmosphere climate model suitable for use in climatic studies due to land surface alterations. J. Climate, 11, 1749-1767. (c) Copyright [1998] American Meteorological Society. Used with permission). 
Since soil moisture content affects atmospheric conditions by influencing not only the soil albedo, but also the evaporation and hence the energy balance at the surface, it is important to incorporate hydrological processes at the surface. [17] incorporated a soil hydrology model based on BATS and the diurnal cycle in [15]. They investigated the physical feedback of the change in surface characteristics associated with precipitation, evaporation, radiation budget and temperature caused by Amazonian deforestation. They showed that the reduction in transpiration was responsible for the most part of the decrease in total evapotranspiration (63\%). The reduction in precipitation was larger than the decrease in evapotranspiration so that runoff was reduced.

Although the SDMs of [15] and [17] were designed to calculate zonal means and not regional features of the Amazonian climate, they allow us to obtain separate simulations for the continental portion of a latitude belt. In South America, most of the continental area of the tropical region is covered by Amazonian forest. Therefore, the effects of Amazonian deforestation on regional climate were analyzed taking into account the model simulations for the land fraction of the tropical region. The simulations must be interpreted as an overall behaviour of climate in the tropical continental region. In general, the changes in temperature and energy fluxes were in good agreement with GCM experiments, showing that the SDMs are able to simulate the characteristics of the tropical climate that are associated with the substitution of forest by pasture areas.

There have been some studies that investigate the role of change in vegetation on the subtropical Africa. The pioneering work of [39] used an analytical zonally symmetric model to study the qualitative effect of increasing surface albedo on Sahelian rainfall. [40] investigated the impact of sub-Saharan desertification on West African rainfall using a zonally averaged model of the West African monsoon. Their justification for using a two-dimensional model is based on the fact that West Africa has a zonally uniform distribution of rainfall, vegetation, and other meteorological quantities. [28] reported some preliminary results regarding the relative importance of tropical deforestation and sub-Saharan desertification. In a subsequent paper, [29] presented a more detailed and complete analysis of the problem. They found that changes in vegetation cover along the border between the Sahara desert and West Africa (desertification) may have a minor impact on the simulated monsoon circulation. However, coastal deforestation may cause the collapse of the monsoon circulation and have a dramatic impact on the regional rainfall. [30] developed a zonally symmetric coupled biosphere-atmosphere model including ecosystem dynamics, and applied this model to study biosphere-atmosphere interactions in the region of West Africa. Using this model, they investigated the role of biosphere-atmosphere interactions in the climate variability over West Africa [31]. They demonstrated that the natural response to local grass ecosystem to the dry conditions of the late 1960s played a critical role in maintaining the drought to the following decades in the Sahel region. In a subsequent paper, they suggested that the vegetation dynamics was a significant process in shaping the natural variability of the Sahel rainfall [41].

\subsection{Climate Change Due to Global Warming}

Because of significant uncertainty in the behavior of the climate system, evaluations of the impact of an increase in greenhouse gas concentrations in the atmosphere require a large number of long-term climate simulations. In this sense, SDMs can effectively be useful due to their computational efficience. [42] described a 2-D zonally averaged model coupled with a difuse ocean model developed for use in the integrated framework of the Massachusetts Institute of Technology (MIT) Joint Program on the Science and Policy of Global Change (MIT 2-D). The atmospheric model was derived from the Goddard Institute for Space Studies (GISS) Model II GCM [43] and used parameterizations of the eddy transports of momentum, heat and moisture by baroclinic eddies [9] [10]. The results showed that globally averaged values and zonal distributions of equilibrium changes in the different climate variables, such as temperature, precipitation, evaporation, and radiation balance at the surface, as produced by different versions of the 2-D model in response to a doubling of the atmospheric $\mathrm{CO}_{2}$, were similar to those obtained in simulations with different GCMs. This model was used in various studies regarding the uncertainties of future climate change due to global warming, such as [44]-[47].

Several studies have examined the impacts of biomass burning in Amazonia on the radiative balance and climate. However, the relative importance of the changes and mechanisms involved has not been investigated. [18] incorporated a detailed radiation model [48] [49] in [15] to study the relative contributions of the changes in the radiation budget and climate caused by smoke aerosols, greenhouse gases and alteration of the land surface characteristics due to biomass burning in the Amazonian forest. To our knowledge, for the first time in that study the effects of the degradation of the surface and smoke aerosols due to biomass burning in Amazonia were 
investigated together. In general, the greater changes in the radiative balance and climate were due mainly to the changes in the land surface characteristics, followed by those caused by the large amounts of smoke aerosols released in the atmosphere. The changes due to the greenhouse gases were small. The degradation of the surface was responsible for the greatest changes in the net thermal infrared radiation $(-14.1 \%)$ and net radiation $(-17.5 \%)$ fluxes at the surface while smoke aerosols seemed to play the main role in controlling the changes in the absorbed solar radiation at the surface $(-9.7 \%)$. The increase of the air surface temperature was $2^{\circ} \mathrm{C}$ and $0.7^{\circ} \mathrm{C}$ in the cases of the degradation of the surface and smoke aerosols, respectively.

[19] used the same model of [18] to evaluate separately each of the four major greenhouse gases $\left(\mathrm{CO}_{2}, \mathrm{O}_{3}\right.$, $\mathrm{CH}_{4}$, and $\mathrm{N}_{2} \mathrm{O}$ ) in order to quantify their contribution to the future climate change. Such a study had not been done earlier. In the control experiment the actual concentration of the greenhouse gases used in the radiation models was obtained from the IPCC TAR [50] while the concentration of the four major anthropogenic greenhouse gases was those of the more drastic IPCC SRES scenario for 2100 (A1FI-2100). They found that the mean global planetary absorbed solar radiation increased in response to the predicted conditions according to the scenario A1FI for year 2100. This was due to the effect of $\mathrm{O}_{3}$ absorptions. These increases led to a decrease in the mean global planetary net thermal infrared radiation emitted to space by the earth-atmosphere system to space and to an increase in mean global planetary net radiation. These changes were controlled mainly by the increase in $\mathrm{CO}_{2}$ concentration (Figure 4). The changes in the radiation budget due to $\mathrm{N}_{2} \mathrm{O}$ and $\mathrm{CH}_{4}$ were small. The change in the air surface temperature response to the predicted conditions for A1FI scenario was mainly controlled by $\mathrm{CO}_{2}$ concentration (Figure 5).

The future biomes distribution can be modified over the entire globe due to global warming, as projected by IPCC AR4 [51]. Because of the importance of the vegetation-climate interactions in the climate system and their social and economic consequences, more studies using several models of different complexity are needed to improve the knowledge of the impact of global warming on the distribution of the biomes over the globe. [20] used a version of [13] for investigating the impact of the increase of $\mathrm{CO}_{2}$ concentration on the future global distribution of geobotanic zones. They included a detailed formulation of the radiative transfer models [52] which is suitable for use in ZACMs [53]. The future climate scenarios were obtained from the IPCC AR4 (2007). The results showed that the geobotanic zones over the entire earth can be modified in future due to global warming.
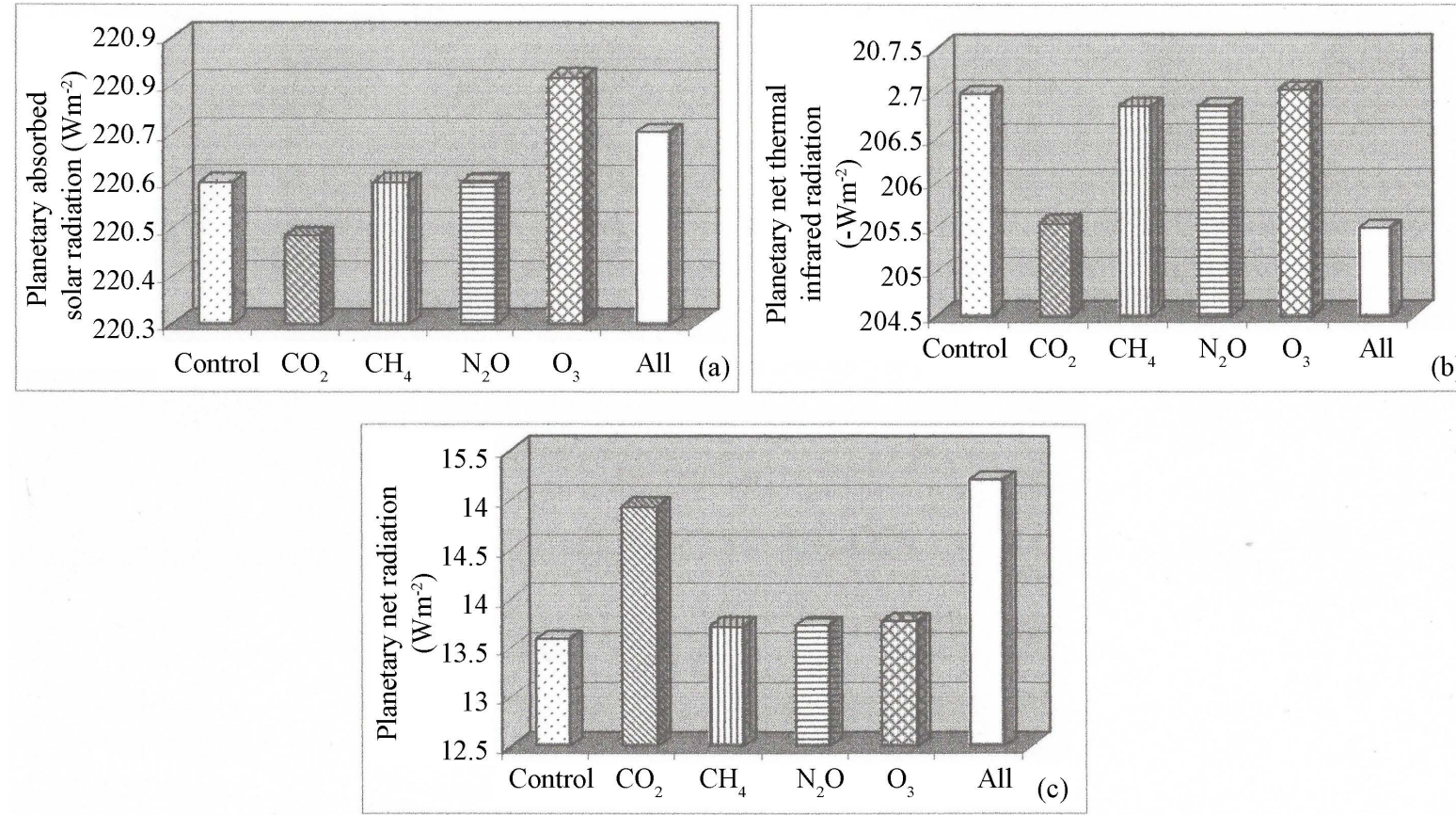

Figure 4. Mean global Planetary (a) absorbed solar radiation, (b) net outgoing thermal infrared radiation, and (c) net radiation at the surface $\left(\mathrm{Wm}^{-2}\right)$. Shown are the values for the five experiments. (Source: Moraes, E. C.; Franchito, S. H.; Rao, V. B., 2005: Evaluation of surface air temperature change due to the greenhouse gases increase with a statistical-dynamical model. J. Geophys. Res., 110. (C) Copyright [2005] American Geophysical Union. Used with permission). 


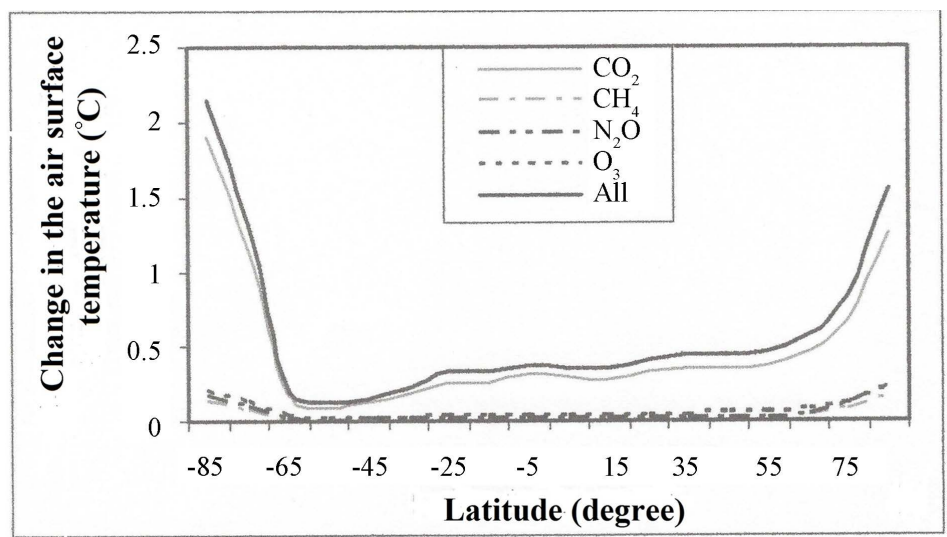

Figure 5. Latitudinal variation of the increase of air surface temperature $\left({ }^{\circ} \mathrm{C}\right)$ (perturbed minus control). Adapted from Moraes et al. (2005) (Source: Moraes, E. C.; Franchito, S. H.; Rao, V. B., 2005: Evaluation of surface air temperature change due to the greenhouse gases increase with a statistical-dynamical model. J. Geophys. Res., 110. (C) Copyright [2005] American Geophysical Union. Used with permission).

Expansion of subtropical desert and semi-desert zones in the $\mathrm{NH}$ and $\mathrm{SH}$, retreat of glaciers and sea-ice, with the Arctic region being particularly affected and a reduction of the tropical rainforest and boreal forest can occur due to the increase of the greenhouse gases concentration (see Figure 27 of [20]). The effects were more pronounced in the A1FI and A2 scenarios compared with the B1 scenario. The SDM results confired the IPCC AR4 projections of future climate and were consistent with simulations of more complex GCMs, reinforcing the necessity of the mitigation of climate change associated to global warming.

[21] used the same SDM of [20] to investigate the impact of global warming on the savannization of the tropical land region and the relative roles of the impact of the increase of greenhouse concentration and future changes in land cover on the regional climate. Their results showed that the climate change due to deforestation was important relative to greenhouse gases at the regional level. The warming due to deforestation corresponded to around $60 \%$ of the warming in the tropical region when the increase of $\mathrm{CO}_{2}$ concentration was included together. However, the global warming due to deforestation was negligible. On the other hand, with the increase of $\mathrm{CO}_{2}$ concentration projected for 2100 the warming was largely enhanced. The impact of the increase of $\mathrm{CO}_{2}$ concentration on a deforestation scenario was to increase the reduction of the areas covered by tropical forest (and a corresponding increase in the areas covered by savanna) which may reach $7.5 \%$ in future compared with the present climate. Compared with the case with only deforestation, drying may increase by $66.7 \%$. This corroborates with the hypothesis that the process of savannization of the tropical forest can be accelerated in future due to global warming.

More recently, [22] investigated the relative importance of the impact of the land change due to tropical deforestation and global warming on the regional energy balance and climate. The results showed that the higher impact on the energy balance was due to the degradation of land. The percentage of the warming due to deforestation relative to the warming when the increase of greenhouse gas concentration was included together was higher than $60 \%$ in the tropical region. This was in agreement with [21] and with other previous studies which suggested that the warming due to deforestation may be important in a regional scale [54]-[56]. On the other hand, with the increase of greenhouse gases concentration an enhancement of the surface temperature occurred. At $5^{\circ} \mathrm{N}$ the increase relative to deforestation was higher than $50 \%$ for the surface temperature and higher than $90 \%$ for the foliage and air foliage temperature.

\section{Latest Advances by Using Statistical-Dynamical Models}

More recently SDMs makes an important part of Earth System Models of Intermediate Complexity (EMICs). EMICs are complex enough to capture essential climate processes and feedbacks while compromising on the complexity of one or more climate model component. The main characteristic of EMICs is that they describe most of the processes implicit in comprehensive models, albeit in a more reduced (i.e., more parametrized) form. 
They also explicitly simulate the interactions among several components of the climate system including biogeochemical cycles. On the other hand, EMICs are computationally efficient enough to allow for long-term climate simulations over several tens of thousands of years or a broad range of sensitivity experiments over several millennia. Currently, there are several EMICs in operation such as: two-dimensional, zonally averaged ocean models coupled to a simple atmospheric module [57] [58] or geostrophic two-dimensional [59] or statisticaldynamical [60] atmospheric modules; three-dimensional models with a statistical-dynamical atmospheric and oceanic modules [61]; reduced-form comprehensive models [62] and those that involve an energy-moisture balance model coupled to an OGCM and a sea-ice model [63]. Results from experiments that were part of the contribution of several EMICs to the 5th Assessment Report of IPCC Working Group 1 are described in [64] [65].

\section{Conclusions}

Manifold physical processes which govern the climate system can be studied using a hierarchy of models. In this paper, a brief discussion of the classification of climate models was given. The advantages of the SDMs were mentioned. Because of their intermediate position in the hierarchy of climate models, SDMs are useful both in the planning of more detailed GCMs and generalizing much simpler 1-D models. For many of the processes where special parameterizations must be developed for a SDM, the questions that force such development are similar to those arising in attempting to treat the subgrid-scale processes needed to improve regional simulations with a GCM. Thus, SDM can and should play an important role in improving understanding of climate system behaviour [66]. Also, SDMs are policy-relevant because they are simpler, faster, and can be used to test specific mechanisms. In this paper, a review of SDMs is presented showing the feasibility of their use to study climate change.

The review presented show that the SDMs are capable of simulating monsoonlike circulations and are useful to study the climate impact due to land surface alterations such as deforestation of tropical Amazonia and desertification of subtropical regions like Sahara as well as the impact of vegetation on the West African monsoon. The SDMs are also useful for studies of the climate effects caused by global warming such as biomass burning in Amazonia and increase of greenhouse gases concentration in future.

\section{References}

[1] Randall, D.A. and Wood, R.A. (2007) Climate Models and Their Evaluation. Climate Change 2007: The Physical Science Basis. Contribution of Working Group I to the Fourth Assessment Report of the Intergovernmental Panel on Climate Change, Cambridge University Press, Cambridge, 590-662.

[2] Rasool, S.L. and Schneider, S.H. (1971) Atmospheric Carbon Dioxide and Aerosols: Effects of Large Increases on Global Climate. Science, 173, 138-141. http://dx.doi.org/10.1126/science.173.3992.138

[3] Budyko, M.Y. (1969) The Effect of Solar Radiation Variations on Climate of the Earth. Tellus, 21, 611-619. http://dx.doi.org/10.1111/j.2153-3490.1969.tb00466.x

[4] Sellers, W.D. (1969) A Global Climate Model Based on the Energy Balance of the Earth-Atmosphere System. Journal of Applied Meteorology, 8, 392-400. http://dx.doi.org/10.1175/1520-0450(1969)008<0392:AGCMBO >2.0.CO;2

[5] Saltzman, B. (1968) Steady-State Solutions for the Axially-Symmetric Climate Variables. Pure and Applied Geophysics, 69, 237-259. http://dx.doi.org/10.1007/BF00874919

[6] Saltzman, B. and Vernekar, A.D. (1971) An Equilibrium Solution of the Axially Symmetric Component of the Earth's Macroclimate. Journal of Geophysical Research, 76, 1498-1524. http://dx.doi.org/10.1029/JC076i006p01498

[7] Saltzman, B. and Vernekar, A.D. (1972) Global Equilibrium Solutions for the Zonally Averaged Macroclimate. Journal of Geophysical Research, 77, 3936-3945. http://dx.doi.org/10.1029/JC077i021p03936

[8] Stone, P.H. (1974) The Meridional Variation of the Eddy Heat Fluxes by Baroclinic Waves and Their Parameterizations. Journal of the Atmospheric Sciences, 31, 444-456. http://dx.doi.org/10.1175/1520-0469(1974)031<0444:TMVOTE>2.0.CO;2

[9] Stone, P.H. and Yao, M.S. (1987) Development of a Two-Dimensiooal Zonally Averaged Statistical-Dynamical Model. Part II: The Role of Eddy Momentum Fluxes in the General Circulation and Their Parameterization. Journal of the Atmospheric Sciences, 44, 3796-3786. http://dx.doi.org/10.1175/1520-0469(1987)044<3769:DOATDZ>2.0.CO;2

[10] Stone, P.H. and Yao, M.S. (1990) Development of a Two-Dimensional Zonally Averaged Statistical-Dynamical Model. Part III: The Parametrization of the Eddy Fluxes of Heat and Moisture. Journal of Climate, 3, 726-740.

[11] Yao, M.-S. and Stone, P.H. (1987) Development of a Two-Dimensional Zonally Averaged Statistical-Dynamical 
Model. Part I: The Parameterization of Moist Convection and Its Role in the General Circulation. Journal of the Atmospheric Sciences, 44, 65-82.

[12] Saltzman, B. (1978) A Survey of Statistical-Dynamical Models of Terrestrial Climate. Advances in Geophysics, 20, 183-304. http://dx.doi.org/10.1016/S0065-2687(08)60324-6

[13] Franchito, S.H. and Rao, V.B. (1992) Climatic Change Due to Land Surface Alterations. Climatic Change, 22, 1-34. http://dx.doi.org/10.1007/BF00143341

[14] Franchito, S.H. and Rao, V.B. (1995) On the Simulation of Sea Surface Temperature with a Zonally Averaged Model. The Global Atmosphere and Ocean System, 3, 3-53.

[15] Varejão-Silva, M.A., Franchito, S.H. and Rao, V.B. (1998) A Coupled Biosphere-Atmosphere Climate Model Suitable for Use in Climatic Studies Due to Land Surface Alterations. Journal of Climate, 11, 1749-1767. http://dx.doi.org/10.1175/1520-0442(1998)011<1749:ACBACM>2.0.CO;2

[16] Rao, V.B., Fernandez, J.P.R. and Franchito, S.H. (2000) Monsoon-Like Circulations in a Zonally-Averaged Numerical Model with Topography. Monthly Weather Review, 128, 779-794. http://dx.doi.org/10.1175/1520-0493(2000)128<0779:MCIAZA>2.0.CO;2

[17] Silva, M.E.S., Franchito, S.H. and Rao, V.B. (2006) Effects of the Amazonian Deforestation on Regional Climate: A Numerical Experiment with a Coupled Biosphere-Atmosphere Model with Soil Hydrology. Theoretical and Applied Climatology, 85, 1-18. http://dx.doi.org/10.1007/s00704-005-0177-5

[18] Moraes, E.C., Franchito, S.H. and Rao, V.B. (2004) Effects of Biomass Burning in Amazonia on Climate: A Numerical Experiment with a Statistical-Dynamical Model. Journal of Geophysical Research, 109, Article ID: D05109. http://dx.doi.org/10.1029/2003JD003800

[19] Moraes, E.C., Franchito, S.H. and Rao, V.B. (2005) Evaluation of Surface Air Temperature Change Due to the Greenhouse Gases Increase with a Statistical-Dynamical Model. Journal of Geophysical Research, 110, Article ID: D24109. http://dx.doi.org/10.1029/2004JD005679

[20] Franchito, S.H., Rao, V.B. and Moraes, E.C. (2011) Impact of Global Warming on the Geobotanic Zones: An Experiment with a Statistical-Dynamical Climate Model. Climate Dynamics, 37, 2011-2034. http://dx.doi.org/10.1007/s00382-010-0952-6

[21] Franchito, S.H., Rao, V.B. and Fernandez, J.P.R. (2012) Tropical Land Savannization: Impact of Global Warming. Theoretical and Applied Climatology, 109, 73-79. http://dx.doi.org/10.1007/s00704-011-0560-3

[22] Moraes, E.C., Franchito, S.H. and Rao, V.B. (2013) Amazonian Deforestation: Impact of Global Warming on the Energy Balance and Climate. Journal of Applied Meteorology and Climatology, 52, 521-530.

[23] Rao, V.B. and Franchito, S.H. (1993) Response of a Simple Model to the Sea Surface Anomalies. Annales Geophysicae, 11, 846-856.

[24] Webster, P.J. and Lau, K.M. (1977) A Simple Ocean-Atmosphere Climate Model: Basic Model and a Simple Experiment. Journal of the Atmospheric Sciences, 34, 1063-1084. http://dx.doi.org/10.1175/1520-0469(1977)034<1063:ASOACM>2.0.CO;2

[25] Webster, P.J. and Chou, L.C. (1980) Seasonal Structure of a Simple Monsoon System. Journal of the Atmospheric Sciences, 37, 354-367. http://dx.doi.org/10.1175/1520-0469(1980)037<0354:SSOASM>2.0.CO;2

[26] Webster, P.J. and Chou, L.C. (1980) Low Frequency Transition of a Simple Monsoon System. Journal of the Atmospheric Sciences, 37, 368-382. http://dx.doi.org/10.1175/1520-0469(1980)037<0368:LFTOAS >2.0.CO;2

[27] Webster, P.J. (1983) Mechanisms of Monsoon Low-Frequency Variability: Surface Hydrological Effects. Journal of the Atmospheric Sciences, 40, 2110-2124. http://dx.doi.org/10.1175/1520-0469(1983)040<2110:MOMLFV>2.0.CO;2

[28] Zheng, X. and Eltahir, A.E.B. (1997) The Response of Deforestation and Desertification in a Model of West African Monsoons. Geophysical Research Letters, 24, 115-158. http://dx.doi.org/10.1029/96GL03925

[29] Zheng, X. and Eltahir, A.E.B. (1997) The Role of Vegetation on the Dynamics of West African Monsoons. Journal of Climate, 11, 2078-2096. http://dx.doi.org/10.1175/1520-0442-11.8.2078

[30] Wang, G. and Eltahir, E.A.B. (2000) Biosphere-Atmosphere Interactions over West Africa. I: Development and Validation of a Couple Dynamical Model. Quarterly Journal of the Royal Meteorological Society, 126, 1239-1260. http://dx.doi.org/10.1002/qj.49712656503

[31] Wang, G. and Eltahir, E.A.B. (2000) Ecosystem Dynamics and the Sahel Drought. Geophysical Research Letters, 27, 795-798. http://dx.doi.org/10.1029/1999GL011089

[32] Potter, G.L., Ellsaesser, H.W., MacCracken, M.C. and Luther, E.M. (1975) Possible Climatic Impact of Tropical Deforestation. Nature, 258, 697-698. http://dx.doi.org/10.1038/258697a0

[33] Ellsaesser, H.W., MacCracken, M.C., Potter, G.L. and Luther, E.M. (1976) An Additional Model Test of Positive 
Feedback from High Desert Albedo. Quarterly Journal of the Royal Meteorological Society, 102, 655-666. http://dx.doi.org/10.1002/qj.49710243311

[34] Gutman, G., Ohring, G. and Joseph, J.H. (1984) Interaction between the Geobotanic State and Climate: A Suggested Approach and a Test with a Zonal Model. Journal of the Atmospheric Sciences, 41, 2663-2678. http://dx.doi.org/10.1175/1520-0469(1984)041<2663:IBTGSA>2.0.CO;2

[35] Ohring, G. and Adler, S. (1978) Some Experiments with a Zonally Averaged Climate Model. Journal of the Atmospheric Sciences, 35, 186-205. http://dx.doi.org/10.1175/1520-0469(1978)035<0186:SEWAZA>2.0.CO;2

[36] Gutman, G. (1984) Numerical Experiments on Land Surface Alterations with a Zonal Model Allowing for Interaction between the Geobotanic State and Climate. Journal of the Atmospheric Sciences, 41, 2679-2685. http://dx.doi.org/10.1175/1520-0469(1984)041<2679:NEOLSA>2.0.CO;2

[37] Nobre, C.A., Sellers, P.J. and Shukla, J. (1991) Amazonian Deforestation and Regional Climate Change. Journal of Climate, 4, 957-988. http://dx.doi.org/10.1175/1520-0442(1991)004<0957:ADARCC $>2.0 . C O ; 2$

[38] Zhang, T. (1994) Sensitivity Properties of a Biosphere Model Based on BATS and a Statistical-Dynamical Climate Model. Journal of Climate, 7, 890-913. http://dx.doi.org/10.1175/1520-0442(1994)007<0890:SPOABM>2.0.CO;2

[39] Charney, J.G. (1975) Dynamics of Desert and Drought in the Sahel. Quarterly Journal of the Royal Meteorological Society, 101, 193-202. http://dx.doi.org/10.1002/qj.49710142802

[40] Xue, Y., Liou, K.N. and Kasahara, A. (1990) Investigation of Biogeophysical Feedback on the African Climate Using a Two-Dimensional Model. Journal of Climate, 3, 337-352. http://dx.doi.org/10.1175/1520-0442(1990)003<0337:IOBFOT>2.0.CO;2

[41] Wang, G. and Eltahir, E.A.B. (2000) The Role of Vegetation Dynamics in Enhancing the Low-Frequency Variability of the Sahel Rainfall. Water Resources Research, 364, 1013-1021. http://dx.doi.org/10.1029/1999WR900361

[42] Solokov, A.P. and Stone, P.H. (1998) A Flexible Climate Model for Use in Integrated Assessments. Climate Dynamics, 14, 291-303. http://dx.doi.org/10.1007/s003820050224

[43] Hansen, J., Russell, G., Rind, D., Stone, P., Lacis, A., Lebedeff, S., Ruedy, R. and Travis, L. (1983) Efficient Three-Dimensional Global Models for Climate Studies: Models I and II. Monthly Weather Review, 111, 609-662. http://dx.doi.org/10.1175/1520-0493(1983)111<0609:ETDGMF>2.0.CO;2

[44] Kamenkovich, L.V., Solokov, A.P. and Stone, P.H. (2002) An Efficient Climate Model with a 3D Ocean and Statistical-Dynamical Atmosphere. Climate Dynamics, 19, 585-598. http://dx.doi.org/10.1007/s00382-002-0246-8

[45] Forest, C.E., Stone, P.H., Sokolov, A.P., Allen, M.R. and Webster, M. (2002) Quantifying Uncertainties in Climate System Properties with the Use of Recent Climate Observations. Science, 295, 113-117. http://dx.doi.org/10.1126/science.1064419

[46] Sokolov, A.P., Schlosser, C.A., Dutkiewicz, S., Paltsev, S., Kicklighter, D.W., Jacoby, H.D., et al. (2005) The MIT Integrated Global System Model (IGSM) Version 2: Model Description and Baseline Evaluation, MIT JP Report 124. http://globalchange.mit.edu/files/document/MITJPSPGC Rpt124.pdf

[47] Solokov, A.P., Forest, C.E. and Stone, P.H. (2008) Sensitivity of Climate Change Projections to Uncertainties in the Estimates of Observed Changes in Deep-Ocean Heat Content. http://dspace.mit.edu/bitstream/handle/1721.1/44624/MITJPSPGC_Rpt166.pdf?sequence=1

[48] Chou, M.-D. and Suarez, M.J. (1994) An Efficient Thermal Infrared Radiation Parameterization for Use in General Circulation Models. Technical Report Series on Global Modeling and Data Assimilation, Technical Memorandum 104606, Goddard Space Flight Center, Greenbelt, 102 p.

[49] Chou, M.-D. and Suarez, M.J. (1999) A Solar Radiation Parameterization (CLIRAD-SW) Developed at Goddard Climate and Radiation Branch for Atmospheric Studies. NASA Technical Memorandum NASA/TM-1999-104606.

[50] Houghton, J.T., Ding, Y., Griggs, D.J., Noguer, M., van der Linden, P.J., Dai, X., Maskell, K. and Johnson, C.A. (2001) Climate Change 2001: The Scientific Basis. Contribution of Working Group I to the Third Assessment Report of the Intergovernmental Panel on Climate Change, Cambridge University Press, Cambridge, 881 p.

[51] Meehl, G.A., Stocker, T.F., Collins, W.D., Friedlingstein, A.T., Gaye, A.T., Gregory, J.M., Kitoh, A., Knutti, R., Murphy, J.M., Noda, A., Raper, S.C.B., Watterson, I.G., Weaver, A.J. and Zhao, Z. (2007) Global Climate Projections. In: Climate Change 2007: The Physical Science Basis. Contribution of Working Group I to the Fourth Assessment Report of the Intergovernmental Panel on Climate Change, Cambridge University Press, Cambridge, 747-845.

[52] Jentsch, V. (1991) An Energy Balance Climate Model with Hydrological Cycle. 1. Model Description and Sensitivity to Internal Parameters. Journal of Geophysical Research, 96, 16169-17179.

[53] Franchito, S.H., Rao, V.B. and Silva, R.R. (1998) A Parameterization of Radiative Fluxes Suitable for Use in a Statistical-Dynamical Model. Meteorology and Atmospheric Physics, 69, 23-38. http://dx.doi.org/10.1007/BF01025181

[54] Maynard, K. and Royer, J.-F. (2004) Effects of "Realistic” Land-Cover Change on a Greenhouse-Warmed African 
Climate. Climate Dynamics, 22, 343-358. http://dx.doi.org/10.1007/s00382-003-0371-z

[55] Feddema, J.J., Oleson, K.W., Bonan, G.B., Mearns, L.O., Buja, L.E., Meehl, G.A. and Washington, W.M. (2005) The Importance of Land-Cover Change in Simulating Future Climates. Science, 310, 1674-1678. http://dx.doi.org/10.1126/science.1118160

[56] Voldoire, A. (2006) Quantifying the Impact of Future Land-Use Changes against Increases in GHG Concentrations. Geophysical Research Letters, 33, Article ID: L04701. http://dx.doi.org/10.1029/2005GL024354

[57] Stocker, T., Wright, F.D.G. and Mysak, L.A. (1992) A Zonally Averaged, Coupled Ocean-Atmosphere Model for Paleoclimate Studies. Journal of Climate, 5, 773-797. http://dx.doi.org/10.1175/1520-0442(1992)005<0773:AZACOA>2.0.CO;2

[58] Marchal, O., Stocker, T.F. and Joos, F. (1998) A Latitude-Depth, Circulation-Biogeochemical Ocean Model for Paleoclimate Studies. Development and Sensitivities. Tellus B, 50, 290-316.

[59] Gallée, H., van Ypersele, J.-P., Fichefet, T., Tricot, C. and Berger, A. (1991) Simulation of the Last Glacial Cycle by a Coupled, Sectorially Averaged Climate-Ice Sheet Model I. The Climate Model. Journal of Geophysical Research, 96, 13139-13163. http://dx.doi.org/10.1029/91JD00874

[60] Petoukhov, V., Ganopolski, A., Brovkin, V., Claussen, M., Eliseev, A., Kubatzki, C. and Rahmstorf, S. (2000) CLIMBER-2: A Climate System Model of Intermediate Complexity, Part I: Model Description and Performance for Present Climate. Climate Dynamics, 16, 1-17. http://dx.doi.org/10.1007/PL00007919

[61] Handorf, D., Petoukhov, V.K., Dethloff, K., Eliseev, A.V., Weisheimer, A. and Mokhov, I.I. (1999) Decadal Climate Variability in a Coupled Atmosphere-Ocean Climate Model of Moderate Complexity. Journal of Geophysical Research, 104, 27253-27275. http://dx.doi.org/10.1029/1999JD900836

[62] Opsteegh, J., Haarsma, R., Selten, F. and Kattenberg, A. (1998) ECBILT: A Dynamic Alternative to Mixed Boundary Conditions in Ocean Models. Tellus, 50, 348-367.

[63] Fanning, A.G. and Weaver, A.J. (1996) An Atmospheric Energy-Moisture Model: Climatology, Interpentadal Climate Change and Coupling to an Ocean General Circulation Model. Journal of Geophysical Research, 101, 15111-15128. http://dx.doi.org/10.1029/96JD01017

[64] Eby, M., Weaver, A.J., Alexander, K., Zickfeld, K., Abe-Ouchi, A., Cimatoribus, A.A., Crespin, E., Drijfhout, S.S., Edwards, N.R., Eliseev, A.V., Feulner, G., Fichefet, T., Forest, C.E., Goosse, H., Holden, P.B., Joos, F., Kawamiya, M., Kicklighter, D., Kienert, H., Matsumoto, K., Mokhov, I.I., Monier, E., Olsen, S.M., Pedersen, J.O.P., Perrette, M., Philippon-Berthier, G., Ridgwell, A., Schlosser, A., Schneider von Deimling, T., Shaffer, G., Smith, R.S., Spahni, R., Sokolov, A.P., Steinacher, M., Tachiiri, K., Tokos, K., Yoshimori, M., Zeng, N. and Zhao, F. (2013) Historical and Idealized Climate Model Experiments: An Intercomparison of Earth System Models of Intermediate Complexity. Climate of the Past, 9, 1111-1140. http://dx.doi.org/10.5194/cp-9-1111-2013

[65] Zickfeld, K., Eby, M., Weaver, A.J., Alexander, K., Crespin, E., Edwards, N.R., Eliseev, A.V., Feulner, G., Fichefet, T., Forest, C.E., Goosse, H., Holden, P.B., Joos, F., Kawamiya, M., Kicklighter, D., Kienert, H., Matsumoto, K., Mokhov, I.I., Monier, E., Olsen, S.M., Pedersen, J.O.P., Perrette, M., Philippon-Berthier, G., Ridgwell, A., Schlosser, A., Schneider von Deimling, T., Shaffer, G., Sokolov, A.P., Spahni, R., Steinacher, M., Tachiiri, K., Tokos, K., Zeng, N., and Zhao, F. (2013) Long-Term Climate Change Commitment and Reversibility: An EMIC Intercomparison. Journal of Climate, 26, 5782-5809. http://dx.doi.org/10.1175/JCLI-D-12-00584.1

[66] MacCracken, M.C. and Ghan, S.J. (1988) Design and Use of Zonally Averaged Models. In: Schlesinger, M.E., Ed., Physically-Based Modelling and Simulation of Climate and Climate Change, Kluwer Academic Publishers, Dordrecht, 755-809. http://dx.doi.org/10.1007/978-94-009-3043-8 4 